\title{
BEYOND DEFINITION: ORGANISING SEMANTIC INFORMATION IN BILINGUAL DICTIONARIES
}

This is a pre-copy-editing, author-produced PDF of an article accepted for publication in the International Journal of Lexicography following peer review. The definitive publisher-authenticated version, IJL 21.1, 2008: 69-93; doi: 10.1093/ijl/ecn002, is available online at: http://ijl.oxfordjournals.org/cgi/reprint/ ecn002?ijkey=MGPzg6lamWwgGVo\&keytype $=$ ref.

\section{B. L. Fraser: Faculty of Classics, University of Cambridge (blf10@cam.ac.uk)}

\section{Abstract}

This paper considers the process of organising semantic information in bilingual dictionaries with diachronic coverage, from selecting the textual source-material to designing the entries. The discussion centres on practical aspects of ancient Greek lexicography. First, the traditional semantic frameworks are described. Then, more recent approaches are noted, notably those of Adrados and of Chadwick, both of which aim to integrate contextual data within a semantic framework. Since the relevance of contextual information varies with lemma part of speech, different configurations are required for entries describing nouns, adjectives, and verbs. These are illustrated by three entries from a Greek-English dictionary currently being written at Cambridge. In order to organise data to this level of specificity, stylistic templates are indispensable, and digital software provides a means of providing them. However, systems designed for writing new dictionaries require different features from those designed for encoding pre-existing texts. A description is given of how the lexicographic requirements of the Cambridge dictionary were met by a user-designed system. ${ }^{1}$ 


\section{Background: types of information in the dictionary entry}

A bilingual dictionary presents three kinds of information: on form, meaning and context. Form includes spelling, dialectal variants, accentuation and quantities, and inflections. Meaning includes translations: single-word equivalents of the lemma in the exit language. Context covers both the real-world and the linguistic environments. The presentation of form is not discussed here, though its role in identifying meaning is considered in 1.2 .1 below. $^{2}$

\subsection{Translations and definitions}

Describing meaning only by a single-word translation is of limited value, because, as theorists like Zgusta (1984) have pointed out, equivalence is asymmetric: word meaning cannot always be precisely rendered by a matching word in another language. Consequently, a number of alternative translations are often offered, cumulatively giving an approximation of the meaning.

However, it is not enough to give multiple translations. As Adrados (1977b: 261) notes, a dictionary must also provide data to distinguish between those translations. The organisation of the entry may sometimes be enough to show (implicitly) how the senses interrelate, but for many words an explicit description, a definition, is also helpful. This serves a similar function in a bilingual dictionary as it does in a monolingual one: that is, by giving a paraphrase of the sense.

A definition may be given for each of the senses of a polysemous word, or, as Chadwick (1996: 21) advocated, each entry may have only one definition. In either case, it calls upon three kinds of information: word-form, and comparative and textual evidence.

\subsection{Establishing meaning: the sources}

1.2.1. Word-form. Modern dictionaries are usually less concerned with a word's etymology than 
its derivation: that is, the transparent combination of morphemes that it contains. ${ }^{3}$ A major factor in choosing the wording of definitions is that, as Chadwick (1996: $21-23)$ notes, in all languages 'nearly all words belong to families' and this kinship or 'family resemblance' is crucial to the determination of meaning. In ancient Greek, affixes make a major additional contribution: we may

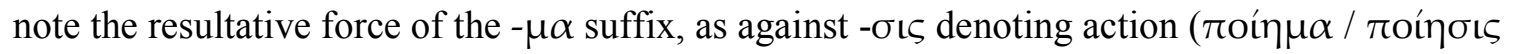

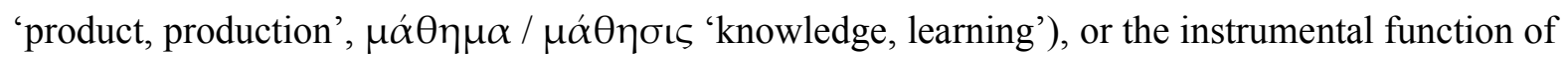

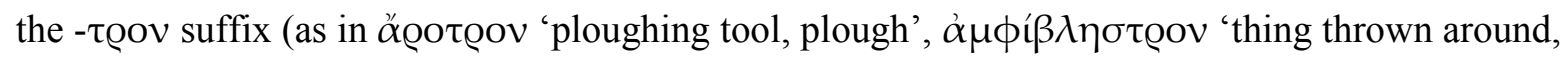

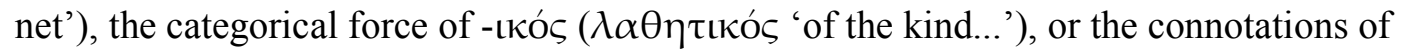

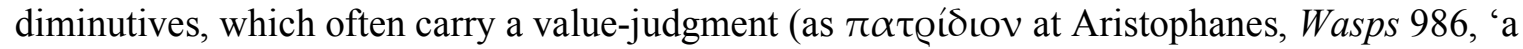
dear father', or í $\alpha \tau \imath \delta$ íoıs at Lysistrata 470, 'poor old cloaks'). Derivational input provides a semantic starting-place for the entry, and helps to map the relationships with words of the same family. A primary reference work is Buck and Petersen (1944), which gives invaluable information on Greek word formation, though naturally we also benefit from more recent research. ${ }^{4}$

1.2.2. Comparative evidence. Derivation is usually of most relevance to the earliest senses. A wider perspective is provided by comparative sources, from bilingual and monolingual dictionaries in other languages. The equivalents in Latin and English can be compared, by consulting works such as the Oxford Latin Dictionary (OLD) and the Oxford English Dictionary (OED), both of which concentrate on semantic patterning.

1.2.3. Usage: textual evidence. The identification of contextual usage takes most of the dictionary-writer's time. First, we have available to us the selection of citations given in existing Greek dictionaries, notably Liddell-Scott-Jones (LSJ), Montanari’s Vocabolario della lingua greca (GI), and the Diccionario griego-español (DGE) and the Lexikon des frühgriechischen Epos (LFgrE) now in progress. But, valuable as these dictionaries are, their data and interpretations are 
only of partial help. Because, as Glare (1987: 17) noted for LSJ, the quotations are too short to confirm meanings, the full textual passages must also be consulted, and, because the citations are also (necessarily) very selective, many other attestations must be examined, to search for further (and especially chronologically-later) meanings.

\subsection{Digital access to the texts}

In ancient Greek, the corpus of extant texts has been almost entirely digitalised, ${ }^{5}$ and so dictionarywriters can make automated searches for every word-form. ${ }^{6}$ However, Greek was a highly-inflected language, with some lemmas having as many as a thousand forms, and so searching for all of them is still a very time-consuming task. A great advance was made with the development of the Perseus morphological analyser, which makes possible integrated searches for every lemma-form: see Crane (1991). And a further resource has been developed for the Cambridge dictionary: because we can predict every word-search that we will eventually want to perform, a program was designed to conduct these searches in advance. Our corpus of texts has been entirely pre-searched for each lemma-form, and the results archived in static HTML (Hypertext Mark-up Language) pages. This constitutes a digital archive of lexicographic 'slips', providing the dictionary writers with immediate access to the searches, and also enabling the citations and their contexts to be archived in a generic format that is not tied to any particular operating system or database program. The design is described by Rydberg-Cox (2005) and its lexicographic use is discussed in Fraser (2008).

\section{Organising meanings}

The next task is to organise the results of our observations into a semantic configuration. And here, beyond definition, we come to the central problem of lexicography, that words generally do not have just one meaning, but their senses vary, in several dimensions, constituting what Adrados 
(1977b: 261) calls a diasystem. The variables may be summarised as chronology, frequency, and context (both extra- and intra-linguistic). Remarks on chronology are given below in 2.2.1 and 2.2.2, and on frequency in 2.2.3. The contextual dimension is discussed at length in Section 4.

\subsection{Hierarchical organisation of senses}

The distribution of the meanings will be reflected in the structures of dictionary entries, which are consequently organised, not as a list, but as a hierarchy of sections and subsections, each of which corresponds to a meaning or sub-sense. In large dictionaries (LSJ, OED, DGE) there may be as many as four levels: overarching Divisions, labelled with capital letters (A, B, C); semantic Branches, with Roman numerals (I, II, II); Sections, with Arabic numerals (1, 2, 3); and Subsections, with lower-case letters $(\mathrm{a}, \mathrm{b}, \mathrm{c}){ }^{7}$ Smaller dictionaries will have a more restricted hierarchy, but the principle is the same.

If all levels are defined semantically, their hierarchical organisation should ensure a clear mapping. However, it may be that hierarchy is more important to dictionary-writers than to readers. It provides a framework in which we can compose, but it is largely invisible to the reader: what they see looks more like a list than a tree. ${ }^{8}$ And at its heart is a major problem: by what criterion can the top-level sections be put in sequence?

\subsection{Criteria for ordering the senses}

The traditional approaches to ordering the sections are described here, together with some suggested points of contact with modern semantic theory.

2.2.1. Chronological. In Greek and English lexicography of the nineteenth and twentieth centuries, the most influential method of ordering the senses was to give them in chronological 
order, in association with examples taken from the literary texts. The first (modern) alphabetic Greek dictionary, and the first dictionary from Greek to a modern language, Schneider (1797 1798), was also the first to give extensive citations to exemplify meaning, but these were taken mostly from early epic, and had little historical range. Passow (1831), in his Handwörterbuch der griechischen Sprache, used Schneider's citations as the basis of his own work, but increased the scope of the citations, in order to map what he called the life-story, the Lebensgeschichte, of each word. The same approach was adopted by Liddell and Scott (1843: v - vi), who cite his remark that he had 'found it necessary to go below Homer and beyond Schneider', and who declare that their own plan 'has been that marked out and begun by Passow, viz. to make each article a History of the usage of the word referred to.'

However, this approach has a major drawback. For any language, and especially an ancient one, the literary evidence does not provide a complete record, and is not enough to determine the order in which meanings developed. So, in their subsequent editions, Liddell and Scott gradually moved away from a Passowian approach, to an order based, not on the recorded sequence, but on an idealised version of it, which visualises changes of meaning as an evolutionary semantic process. ${ }^{9}$

2.2. Logical. The assumption underlying this idealisation was described by Murray (1888: xxi), who adopted a similar approach in the OED: 'If ... we possessed written examples of all the uses of each word from the beginning, the simple exhibition of these would display a rational or logical development. The historical record is not complete enough to do this, but it is usually sufficient to enable us to infer the actual order.'

This method is termed logical (Murray 1888, Hiorth 1955, Zgusta 1987), because it is based on an assumption that the historical development of senses can be placed in a logical sequence, of spatial before temporal before abstract and figurative. This application of logical categorisation to chronology can be defined as semantic ascent (Quine 1960: 270 - 276, Lyons 1989), summarised in the phrase 'ontology recapitulates philology', and is ultimately based upon localist principles 
(Hjelmslev 1935, Lyons 1977: 718 - 724). ${ }^{10}$ It frequently differs from the historical evidence.

Liddell and Scott (1843: viii) wrote: 'Homer will sometimes use a word in a metaphorical sense only, the literal sense of which first occurs (perhaps) in Plato. In such instances ... we give the literal and actual sense the preference.' Most historical dictionaries follow this practice (as explained by Murray 1888: xxx, Adrados 1986a: 22), though a concrete-abstract ordering may not always be

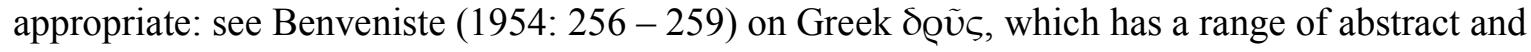
concrete senses, including 'trust', 'tree', and 'oak', and the abstract sense may well have preceded the others.

In addition to a literal-abstract sequence, other generalisations are involved. A secondary principle is to put general senses before more specific ones. Generality can be interpreted semantically in terms of scope: that is, the potential for multiple interpretations of the lemma (Lyons 1977: 152, Rice 2000: $24-50) .{ }^{11}$ Unfortunately, this principle may conflict with the previous one, because, as Ullmann (1972: 119) notes, a general meaning can be considered as more abstract: for $\delta \varrho \tilde{c} \varsigma$, the sense 'tree' is more abstract than 'oak'. ${ }^{12}$ A third principle is animate-first: when giving the semantic range or context of a word, application to persons precedes application to things. ${ }^{13}$ Finally, we can use a moral or evaluative criterion: so a neutral sense precedes a positive connotation, which precedes a negative one. Again, this doesn't always correspond to the observed chronology, in which neutral meanings do not always precede. In their earliest attestations, colour terms are associated with a great range of value-judgements, as also are words for size: $\mu \varepsilon \dot{\gamma \varepsilon \theta o \varsigma}$

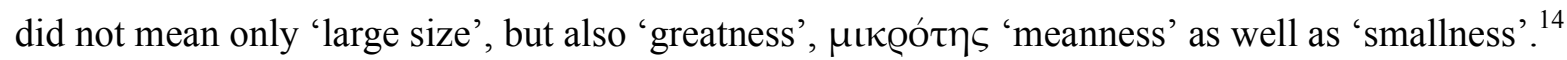

This combination of philosophical, historical and semantic criteria is highly eclectic, but its underlying assumption is that simplicity precedes complexity. This is a useful practical guide, but its semantic basis is not secure, and its link to chronology is no more certain, particularly for grammatical words (adverbs, particles, prepositions and conjunctions), where there is less evidence for development of meanings. ${ }^{15}$ Even more seriously, it will not always be convenient for the reader, who may find it difficult to navigate through an entry to the required sense. 
2.2.3. By frequency. An alternative criterion for ordering the top-level senses is by frequency, with the most common uses first, in what is usually called empirical order (Casares 1950: 67 - 68, Hiorth 1955: $418-423) .{ }^{16}$ This is convenient for the reader, who is (statistically) more likely to find the required usage early in the entry. However, it does not provide a mapping of the full linguistic diasystem, because (like a purely historical approach) it depends on textual happenstance rather than semantic criteria. The problem is particularly severe for ancient languages, as the more common meanings may not be those which are most frequently attested in the texts.

2.2.4. Syntactic. For verbs, a syntactic organisation is often adopted. For example, differences in

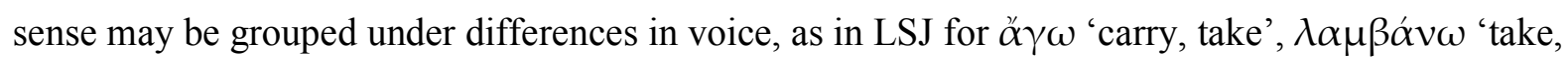
seize', and ő $\lambda \lambda v \mu \mathrm{\iota}$ 'destroy, perish'. In each of these entries, one top-level Division is devoted entirely to the middle voice. This is a strategy which can appear to be more for the convenience of the writer, and it should be used with caution, as it risks obscuring semantic similarities. Although verbal meaning is inextricably linked with syntax, the mapping is not exact: active and middle are not in opposition, and aspect does not map precisely onto tense. ${ }^{17}$

A syntactic organisation is especially common for grammatical words like prepositions, where meanings are standardly listed by the case of the governed noun, so that accusatives, genitives and datives mark the top sections in the hierarchy, as in the LSJ and DGE entries for $\dot{\alpha} v \alpha$ 'up'. This is not, however, the only possibility. We could alternatively give the semantic groupings first, subdivided by the governed cases. There is even an argument for grouping them by their governing verb: most prepositions also have adverbial functions, and their meanings vary with verbs of motion or position. The meaning of $\kappa \alpha \tau \alpha$ ' down', for example, may be better categorised by its verb type than under its governed case (because both accusative and genitive can refer either to motion or to position). We would also wish to consider the common usages of these words as prefixes. $^{18}$ 


\subsection{Compromise between criteria}

It may be concluded that the sections can be defined semantically, but the order in which they are listed must be something of a compromise. This is partly because the semantic tree stops at the toplevel sections, which are (necessarily) placed in linear sequence. Attempts have been made to imply a complete hierarchy, most notably by an idiosyncrasy of labelling in LSJ, where the 'A' of the first Division and the ' 1 ' of the first Section are always omitted, so these can be interpreted as somehow higher in the hierarchy than their siblings. OED uses a similar device, omitting 'a' for the first Subsection, and sometimes omitting ' $\mathrm{A}$ ' for the first Division. But, despite the rationale of these category-cheats (my term), the significance of the missing labels is almost certainly not clear to the reader. We could add an introductory summary linking all the top-level sections, but this is generally impractical, for reasons of space. Most commonly, the first definition serves as a summary.

In sum, there appears to be a considerable disjunction of 'logical' ordering from semantic theory. Adrados (1977b: 261) even includes the method among errors which 'only apparently put order in the chaos of translations.' And yet, no satisfactory alternative has been found for capturing the full historical dimension. The solution usually adopted has been to downplay the historical factors (which can be relegated to the author listings), and to interpret semantic patterning in a more synchronic way. ${ }^{19}$ This is described in the next part of the paper.

\section{Unified approaches to ordering meanings}

Psychological coherence was chosen as an ordering principle in the first edition of the American Heritage Dictionary. Morris (1969, 1975: xlvi) described the method as 'an effort to arrange a complex word in a psychologically meaningful order ... so that the word can to some extent be perceived as a structural unit rather than a string of unrelated senses'; see Kipfer (1984: 103 - 104) 
for further description. This approach was not intended for a scholarly readership, though it could be developed theoretically, perhaps within a relational framework; see Fellbaum (1998).

One of the first modern lexicographical approaches to be systematically based on a semantic model is that of Adrados (1977a, b), which sets out to produce un mapa semantico of the distributions of meanings, in the syntagmatic and paradigmatic dimensions defined by Saussure (1916: 170 - 175). This requires lemmas to be described, on the one hand, in terms of their contextual relations with other words, and, on the other, in terms of their oppositions to words of different meaning. This aim underlies the work of the DGE, the great Greek-Spanish dictionary in progress since 1980; see further Adrados (1997, 2000).

A similar approach has been adopted in Greek-English lexicography, for practical rather than theoretical reasons. In their work on the Oxford Latin Dictionary and on the LSJ Revised Supplement, John Chadwick and Peter Glare concentrated on correcting the factual errors which they found in previous dictionaries, and on improving the semantic groupings (Chadwick 1994, 1996; Glare 1987, 1997). And, drawing also on his experience as a cryptographer, Chadwick (1996: $3-6,20-23)$ concluded that contextual analysis could be combined with word kinship (see 1.2.1 above) in order to arrive at the meaning of each lemma. He considered that the addition of extensive new contextual information would be most practicable in an intermediate-sized lexicon, and in 1998 he founded the Cambridge dictionary project. Under the editorship of Anne Thompson, this is now developing his method of giving detailed descriptions of the contexts of lemmas.

\section{Contextual information in the Cambridge dictionary}

As the Cambridge dictionary is written for students, it has certain practical advantages in putting contextual information at the heart of its method. Because it gives few Greek quotations, more space can be given to semantic description. And, as the citations are restricted to a canon of seventy authors, omitting fragmentary texts and inscriptions, meaning is usually identifiable from context. 


\subsection{Paradigmatic information: noun entries}

Historical dictionaries tend to concentrate on what Firth (1957: 175) called the 'context of situation' because the evidence for the meaning of a word depends largely on its literary connotations, and on the words to which it may be given in opposition.

In the Cambridge dictionary, terms in opposition, literary connotations, and encyclopaedic information, are given in explanatory parentheses. Real-world reference is often described in a definition, though many concrete senses may just require translational equivalents. The approach

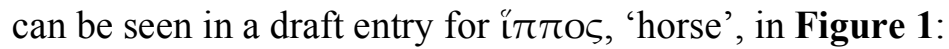

The entry layout is quite traditional, but the content focuses on contextual and literary information, which is presented in a systematic order. The forms are given first, plus part of speech, a derivation, and the inflections. It is notable that the word changes gender, being usually feminine in epic poetry, and that the dual is common. Both these iாmos ov m.f. [íkFos or sim; reltd. Latin equus] | gen dat.du. i 1 horse or mare (high-status animal, oft. in the chariot-teams of men or gods, also for riding; not usu. for draft labour) Hom. +; (pl., assoc. w. Poseidon, esp. as his

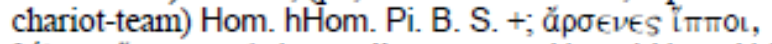

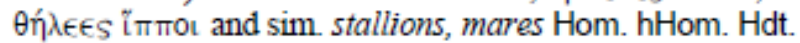
PI. X. Plu.; (fig.) $\dot{\alpha} \lambda$ òs immo horses of the sea (ref. to ships) Od. 2 || DU. or PL. (usu. FEM.) pair, team (of chariot-horses) II. Trag.; (hence) chariot and pair, chariot Hom. 3 || pL. chariots (w. their warriors, opp. foot-soldiers) Hom.; (also later) horses, cavalry Th. Plb. Plu. $4 \mathrm{FEM}$. (collectv.sg.) cavalry, horse (sts. w. pl. number giving total) II. A. Hdt. Th. X. Plb. Plu. 5 (ref. to the Trojan horse) Od. E. Plb.; (app. ref. to a kind of torture) Plu.

6 iтாо о пота́ $\mu$ os river-horse (ref. to the hippopotamus) Hecat. Hdt. Arist. Str. Plu.

i immo- prfx. large or coarse (w. pejor. connot.) | see

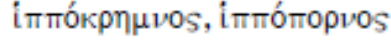

features have extra-linguistic

significance, reflecting the narrative environment.

The order in which the sections are given is based more on scope (with a general $>$ specific sequence of senses) than on frequency (though here, these are not in opposition). The reader will know what a horse is, so a descriptive definition is not needed. We do need to know that it appears in literature in contexts of war-chariots and, later, of cavalry and aristocratic riding, but rarely as a draft animal, and that is given in an explanatory parenthesis. A link with Poseidon is noted, ${ }^{20}$ and also collocations with adjectives denoting male and female. Section 1 ends with a figurative 
expression, referring to ships.

Section 2 gives transferred senses, referring to teams or pairs of horses, or to chariots, and section 3 gives the collective plural chariots, in opposition to foot-soldiers ( $\pi \varepsilon \zeta$ oú). The two sections are introduced by double bars, which indicate a major syntactic change: here, of number. ${ }^{21}$ In section 4, a singular collective sense is given, of horse as cavalry.

It will be seen that there are points of contact with the Passowian Lebensgeschichte. Although the senses are not organised in chronological order, which is given here only in the listings of authors, these do show that the basic sense of 'horse' or 'mare' appears (as we would expect) throughout Greek ('Homer +'), while the other senses have more restricted distribution, and the dual sense of a 'team' of horses (and its transferred sense for a 'chariot') appears only in epic poetry (though the dual appears also in Plato). And the collective singular 'horse' (for cavalry) persists into Koine Greek, alongside a collective plural ('horses, cavalry').

\subsection{Linguistic context: adjectives}

If we turn from extra-linguistic to intra-linguistic context, we come to the syntagmatic dimension. This is realised in collocations, a term introduced by Firth (1957: 179), who famously wrote: 'You shall know a word by the company it keeps'. For the noun 'horse' in Figure 1, a collocation appears in the figurative use in the first section ( $\alpha \lambda$ ò $\varsigma$ í $\pi \pi \mathrm{ol}$ 'horses of the sea'), and in the sixth section

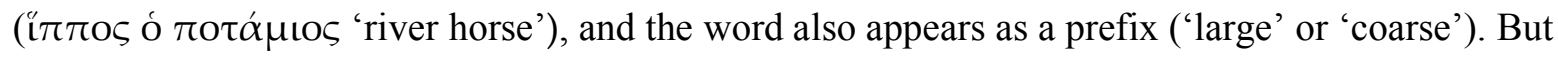
the entry focuses more on paradigmatic meaning, independently of grammar.

It is quite different for other word-classes. Adjectives agree with their qualified nouns, and subjects with their verbs, and of course agreement constitutes only one type of grammatical relationship. Firth (1957: 181) described the full set of relations as colligations, but it may be more simply termed grammatical information. 
In the Cambridge dictionary, the collocational and grammatical information is combined, by giving the words in agreement or in governing or governed relationships with the lemma. This information is given in a fixed sequence, as may be seen from an adjectival entry, for $\sigma u ́ \mu \mu \varepsilon \tau \varrho o \varsigma$,

given in Figure 2:

In this entry, meaning and context are

closely interrelated: the word's

derivational meaning is quite clear

('having the same measure'), but is

applied in a wide variety of contexts,

including physical dimension,

temporal extension, and more abstract

relationships and purposes.

Consequently, nearly every section has

an introductory definition, preceding

the contextual details.

These definitions not only

describe each semantic field, but also

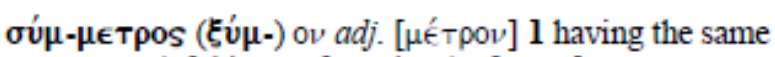
measure; (of things, of numbers) of equal extent or magnitude, commensurate (sts. W.DAT. or mpós $+\mathrm{ACC}$. W. sthg.) PI. Arist. Plu.; (of a footprint) -W.DAT. $w$. another's foot $\mathrm{E}$.; (transf., of a person, ref. to moral stature) -W.DAT. w. other persons Isoc.; (math.) reducible to a common measure, commensurable PI. Arist.

2 of equal duration; (of a person) equal in age (to someone) S.; (of a firebrand) coterminous (w. someone's life) A. 3 of corresponding extent or magnitude; (of height) proportionate (to length and breadth) $\mathrm{PI}$; (of things) -w. про́s + Acc. w. sthg. Arist.; (more loosely, of a lock of hair) matching, comparable - W.DAT to another's hair A.(dub.) 4 of sufficient or proportionate measure; (of terrain, resources, activities) suitable, appropriate (for sthg.) Isoc. PI. Arist. Plb. Plu.; (of advice) A.; (of words of praise) catching the measure (of), adequate -W.DAT. for someone Isoc.; (of a speech) consistent -W.DAT. w. sthg. Isoc. 5 in right measure; (of things, a shape, a person) suitably proportioned PI. Arist.; (of a dining-room) X.; (of hares, their bodies) $X$.; (of things, places) suitable in size, moderately sized Plb. Plu. $\|$ NEUT.SB. due proportion, proper measure $\mathrm{PI}$. 6 (of a person, ref. to his arrival) suitably timed - W.DAT. for sthg. S.; at a suitable distance, within range (for hearing) $\mathrm{S}$.

7 in accord with metre; (of the spelling of a name) suited to the metre S.eleg.; (of dancers) keeping in time Tim.

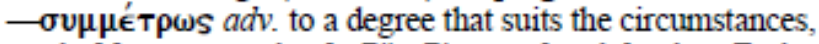
suitably, appropriately $\mathrm{Plb}$. Plu.; at the right time $\mathrm{E}$.; in the right proportion Isoc. PI. X.

serve as what Zgusta $(1987: 267,272)$ calls semantic bridges, guiding the reader between the senses, in a logical rather than chronological sequence. In this way, readers should find the information they seek as quickly as possible, because, by looking at the start of a numbered section, they should be able to see not only whether it contains the likely relevant sense, but also how that sense follows from the previous one.

In the remainder of each section, the translations are given with their contexts, in a regular order. First, a parenthesis gives either the general context, or translations of the qualified nouns appearing with that sense: in section 6, '(of a person, referring to his arrival)'. A translation of the lemma follows in bold ('suitably timed'), itself sometimes followed by an explanatory parenthesis, 
then any dependent constructions in italic ('W. DATIVE for something'), and then a note of authors using that sense (here, only Sophocles).

This is not merely a sequence, but also a hierarchy, defined by the governing relations between the lemma and its collocations, which are presented in order of descending scope. Major syntactic changes (marked by double bars) are given last in their sections. In this entry, there is only one: the substantival usage in section 5 ('due proportion'). The adverb in - $\omega \varsigma$ is given as a subentry.

\subsection{Intra-linguistic context: verbs}

An analogous sequence of grammatical information is used for verbs. Here, subjects and complements (including direct and indirect objects, and clausal complements) are given, again ordered by governing relations. $^{22}$ And, because the exit language, English, has the same ordering (SVO), it is always clear, for example, whether of persons refers to a subject or a complement (in contrast to LSJ, whose lack of clarity in this respect is described by Glare 1987: $12-13$ ).

Details can be seen in an entry for $\sigma v \mu \beta \alpha i ́ v \omega$ 'come together' given in Figure 3:

This word also has a clear meaning ('come together'), which is applied in a variety of contexts. In this instance, the sections have not been given introductory definitions (as in Figure 2), but are organised by the verbal subjects, which precede the $\sigma v \mu-\beta a i(\nu \omega(\xi \nu \mu-) \nu b$. | pass.: 3sg.aor.subj. $\xi v \mu \beta a \theta \hat{n}$, pf.inf. $\xi v \mu \beta \in \beta a ́ \sigma \theta a l$ (Th.)|

1 (of natural elements) come together, meet Emp.; (of groups of people) -W.DAT. w. each other X.; (of arrangements) -W.PREDIC.ADJ. in a close fit $\mathrm{A}$. $\|$ PF. (of a person) stand with feet together $X$.

2 (of adversaries) come together in agreement, come to terms, make an agreement (oft. W.DAT. w. someone, also w. mpós + ACC. Th.) E. Th. Ar. PI. -W.INDEF.ACC. on sthg. Ar. Th. -W.INF. to do sthg. Th. - W.ACC. + INF. (also w. $\tilde{\omega} \sigma T \epsilon$ Hdt.) that someone should do sthg. Hdt. Th. || PAss. (of peace terms) be agreed Th. || PF.ACT. (of peoples) have come to terms, be in agreement $\mathrm{Hdt}$. Th.

3 (of a god, a human) be on close terms - W.DAT. $w$. someone $\mathrm{E}$. Ar.

4 (of time, reports, oracles) correspond, match, tally -W.DAT. w. sthg. Hdt. S. Lys.; (intr., of periods of time, oracles) come out right, tally Hdt. S. Ar.; (of a god's plans) coincide, chime in -W.DAT. w. someone's troubles $\mathrm{E}$. 5 (of events, circumstances) happen, occur Th. Att.orats. Pl. +; happen - w.I. to occur Hdt. Th.; (of things) -W.PTCPL. to exist PI. D. || IMPERS. it happens, it turns out -W.ACC. + INF. (sts.w. sthg. is the case Hdt. S. Th. Att.orats. + \| NEUT. PTCPL.SB. chance event, contingency PI. X. Is. Arist. Plb. 6 (of sufferings, pleasures, responsibilities and sim) fall to the lot of, befall, come the way of - w.DAT. someone $\mathrm{E}$. Th. Att.orats. + || IMPERS. it is (someone's) lot, it falls - W.DAT. + $\mathrm{INF}$. to someone, to do sthg. Hdt. Th. Att.orats. X. Arist. Theoc.

7 (of oracles) turn out, be fulfilled A.; (of predictions) turn out -W.PREDIC.ADI. true S. E.; (of events, oracles) -W.ADV. well, badly, contrary to expectation $\mathrm{Hdt}$. E. Th. X.; (of persons, their actions) turn out -W. PREDIC. ADJ. or SB. as hateful, as an injustice S. PI.; (of an endeavour) turn out well, work out Th. PI.; (ref. to a measurement or calculation) work out (to), add up -W. $\in$ is + ACC. to a specified result A. X. D.

$\mathbf{8}$ (of consequences) result, follow Th. D.; (of logical conclusions) PI. D. Arist.; (of a process) turn out -W.INF. to consist of sthg. PI. || IMPERS. it follows (logically) -W.ACC. + INF. that sthg. is the case PI. Arist. || NEUT.PTCPL.SB. contingent attribute, property (of sthg.) Arist. 
translations. These subjects are given in introductory parentheses, sometimes followed by plain-text definitions (in section 2 'come together in agreement', and 6 'fall to the lot of...'), then bold translations, and author abbreviations. Dependent constructions follow, in italic.

Syntactic changes are noted within the numbered semantic sections, in sub-sections introduced by double bars, as for the stative perfects in sections 1 and 2 ('stand ...', and 'be in agreement'). Three impersonal usages are given in their appropriate positions in the semantic framework, in sections 5, 6 and 8 ('it happens', 'it is (someone's) lot', 'it follows'). Finally, substantival usages appear in sections 5 and 8 ('chance event', 'contingent attribute').

Section-grouping by verbal subjects enables their thematic roles (as agent, patient, goal) to be highlighted. Their functions are described in English, phrased in general terms where possible, as in section 8 above, for functional translations for the subjects ('of consequences', 'of a process') and complements ('that something is the case'). ${ }^{23}$

There is also a more general advantage: by introducing sections with verbal subjects, rather than only with the senses of the lemma, the logical principles of sense-ordering can be applied to the grammatical context. For example, the senses relating to persons and to gods are grouped together, and precede the senses relating to events and logical relationships. It will be noted that, in both adjectival and verbal entries, the semantic groupings dominate the structure, and diachronic information is considerably less prominent.

\subsection{Intra-linguistic context: grammatical words}

Although there is no space here for a discussion of grammatical words, similar principles apply. Prepositions were briefly considered above in 2.2.4, where the importance of their adverbial function was noted. We therefore note the type of verbs which govern each preposition, as well as the cases they govern. 
For conjunctions, the historical criterion can fail completely, and a purely functional description will often be more appropriate, and this can also be organised by context, with illustrative quotations being especially helpful. It may sometimes be possible for the ordering of senses to imply a historical sequence, on the basis of grammaticalisation: for example, that the

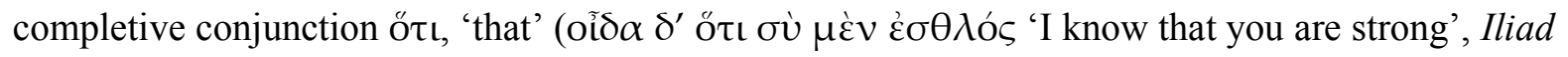

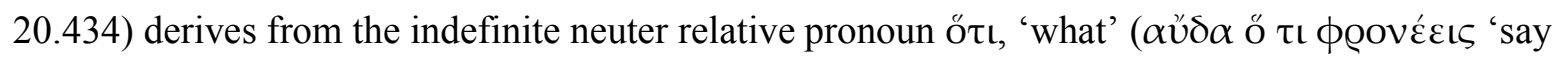

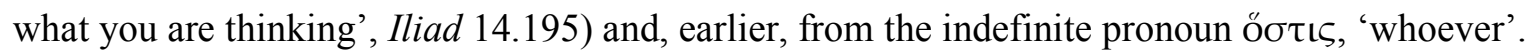
But this will not be of interest to most readers, who will be seeking to identify grammatical functions, which are distinct, even in the earliest texts. ${ }^{24}$

For particles, function and collocational information are even more closely linked, and the translations play a subordinate and illustrative role. For Wackernagel's-law clitics, summaries can be given of the regular collocations with prosodic hosts which are conjunctions ( $\dot{\alpha} \lambda \lambda \dot{\alpha} \gamma \dot{\alpha} \varrho, \varepsilon \hat{\imath}$ $\gamma \alpha ́ \varrho, \kappa \alpha i \gamma \alpha \dot{\varrho}$ etc.). Chronological information will appear only at the lower levels, in the author listings.

\subsection{Entry structure}

The adjectival and verbal entries shown above have structures in which contextual information is very prominent, in contrast to the more parenthetic style of the noun entry. Context is present in all three entries, but is presented in different ways, using specific templates. Reasons why entry structures have not previously been configured according to part of speech are considered below in Section 5 . 


\section{Dictionaries and part of speech}

A different treatment for each part of speech was originally developed for purely practical reasons: to help us organise the semantic descriptions clearly. But theoretical factors may also be involved, as in the WordNet relational model, in which words are grouped into semantic domains using classspecific criteria, such as hyponymy for nouns, entailment for verbs, synonymy and antimony for adjectives: see Fellbaum $(1998$ : chapters $1-3) .^{25}$

Why have differences between word-classes received little attention in lexicographic theory? Three main reasons may be identified:

\subsection{Category overlaps}

There are many overlaps between grammatical categories, as a single lemma can have verbal, nominal, and adjectival functions. It is especially difficult to decide whether to categorise a word as noun or adjective: Greek dictionaries generally avoid the problem by omitting part-of-speech labels, but it seems worth always giving them. Part of speech can be decided on the basis of form, and so words which are formally nominal, but are used with a purely adjectival function, can still be

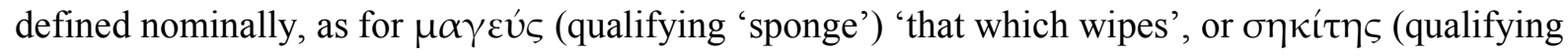
'lamb') 'one kept in the fold'. And, just as we mark appositive uses of nouns, so we also note

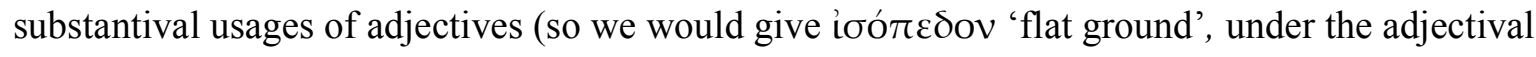
entry for iðó $\pi \varepsilon \delta o \varsigma$ 'level, flat').

The discipline of such categorisation by form has a semantic value. And as contextual meaning differs regularly between parts of speech, it is always possible to use a dedicated structure for each category, even for words which function in more than one. In this way, the similarities, as well as the differences, between the grammatical categories can be organised in a regular way. 


\subsection{Unequal frequencies}

A second reason for the neglect is the inequality in relative frequency of word categories. The great majority of lemmas in a Greek dictionary are nouns or adjectives. As evidence, we may take the 36,467 headwords in the IGL, the Intermediate Greek Lexicon. Of these, grammatical words comprise about $1 \%$; verbs about $29 \%$; and nouns and adjectives together about $70 \%$ (including associated adverbs in - $\omega \varsigma$, which comprise about $8 \%$ of the whole). ${ }^{26}$ So, it is quite natural that referring words (and the paradigmatic dimension) have received most attention, even if, as a result, the treatment of other word classes has sometimes been less satisfactory.

\subsection{Lexicographic language}

In practical terms, it has not been easy to create a specific style for each part of speech, because historical dictionaries are not merely organised as lists of items, but are written in continuous text, which encourages stylistic freedom. And yet, lexicographic writing is typically highly-organised. The use of templates can help us regularise the presentation of each word-class, and digital textediting software gives an opportunity to design such templates.

\section{Digitising entry structure: the Cambridge experience}

The Cambridge group initially adopted a digital platform purely as a publishing system, to facilitate the formatting and proof-reading for the published edition, but soon realised that it could also be helpful in the writing process, and especially in the organisation of contextual information. 


\subsection{Relational database or XML (Extensible Mark-up Language)?}

A relational database management system (RDMS) could have provided great precision. However, it would be less suitable for composing continuous text, and its structure would be relatively

cumbersome to modify. ${ }^{27}$ An RDMS may, of course, be suitable for a 'modular' style of composition, suitable for a concise dictionary, and in fact such a system has been chosen for the Dicionário de Grego-Português. ${ }^{28}$ Our need was for a precise structure, but a less compartmentalised one, and that pointed towards an XML environment.

A second major advantage of XML is that any number of entries can be combined in one document. It is especially useful to be able to compare entries with alphabetically adjacent ones during the writing process. As noted above in 1.2.1, this is of great value in identifying meaning.

\subsection{Pre-existing DTDs (Document Type Definitions)}

It became clear that existing DTDs were not suitable, not because of any flaw, but because they were designed for a different purpose: capturing the variations of existing texts. We started by examining the SGML (Standard Generalized Mark-up Language) DTD used for the second edition of the OED (probably the first mapping of the linguistic form of dictionary entries onto a digital structure), and its adaptation for the online third edition (see Tompa 1996, Elliot 2000). It seemed promising because it was designed for a highly regular writing-style. As Simpson and Weiner (1989: liii) wrote, 'The structure devised by Sir James Murray and used by him and all his successors for writing dictionary entries was so regular that it was possible to analyse them as if they were sentences of a language with a definite syntax and grammar. They could therefore be parsed.' This was not in fact attempted: the mapping is not highly 'granular', and the structure appeared to be unsuitable as an authorial (rather than revising) tool. 
We reached a similar conclusion on the Text Encoding Initiative (TEI) dictionary DTD, a well-known XML model. ${ }^{29}$ Its fundamental drawback is the 'mixed-content' structure of its elements, each of which has over 60 children: that is, an element may contain any amount of text inside it, plus 60 subordinate elements, which may appear any number of times, in any order, interspersed in any way with the text. This structure also seemed unsuitable for our requirements.

\subsection{Requirements for an authorial XML structure}

It was, of course, possible that other models might have provided greater precision. However, it was clear that any pre-existing system would have its limitations: because the organisation of our entries was at this stage quite experimental, no structure, however subtle, could precisely map it. So it was decided to turn this fact to our advantage, and to design the system as we wrote the dictionary, starting with a DTD based on a provisional entry structure, which could be refined as we met new lexicographic problems, until it reached a useful level of precision. ${ }^{30}$

It was essential that the system should not just create extra work for the writers, but should, from the start, assist composition. Above all, time should not be wasted in 'double-handling': that is, first composing the text of an entry in a word-processing document, and then importing it into the editing software and adding the XML tags. Instead, we decided to compose within the XML environment, and dispense with word-processing software, other than for writing preliminary outlines for the more complex entries.

It was therefore vital that the writers could understand the system, both in its details and in their configuration, so the name of each element had to describe its function clearly, and the writers must not be faced with a confusing choice of elements. And all elements should have pre-set attributes, so they would be simple for the writers to insert. In sum, the structure should distract the writers as little as possible from their task. 


\subsection{Meeting the requirements: developing constraints}

6.4.1. A maximally-constrained configuration. It became evident that the optimum configuration was a hierarchy whose top levels contained no mixed-content elements, but only standard-content elements, which have a more rigid structure. ${ }^{31}$ Mixed-content could be allowed at the lower levels, where flexibility was needed to describe variations of detail. Throughout the hierarchy, the writers never have a choice of more than 10 elements at any point, and usually fewer.

6.4. 2. Parallel development. Intensive development took about three years, and proceeded in parallel with the writing process. During this period, different structures were developed for nouns, adjectives, verbs, prepositions, and adverbs. And, because we were almost always adding constraints to the structure, the XML framework and our writing style developed together, and informed each other. 


\subsection{The writer's viewpoint: the XML structure for a noun entry}

The XML structure underlying the entry for ítros (seen in Figure 1) is shown in Figure 4:

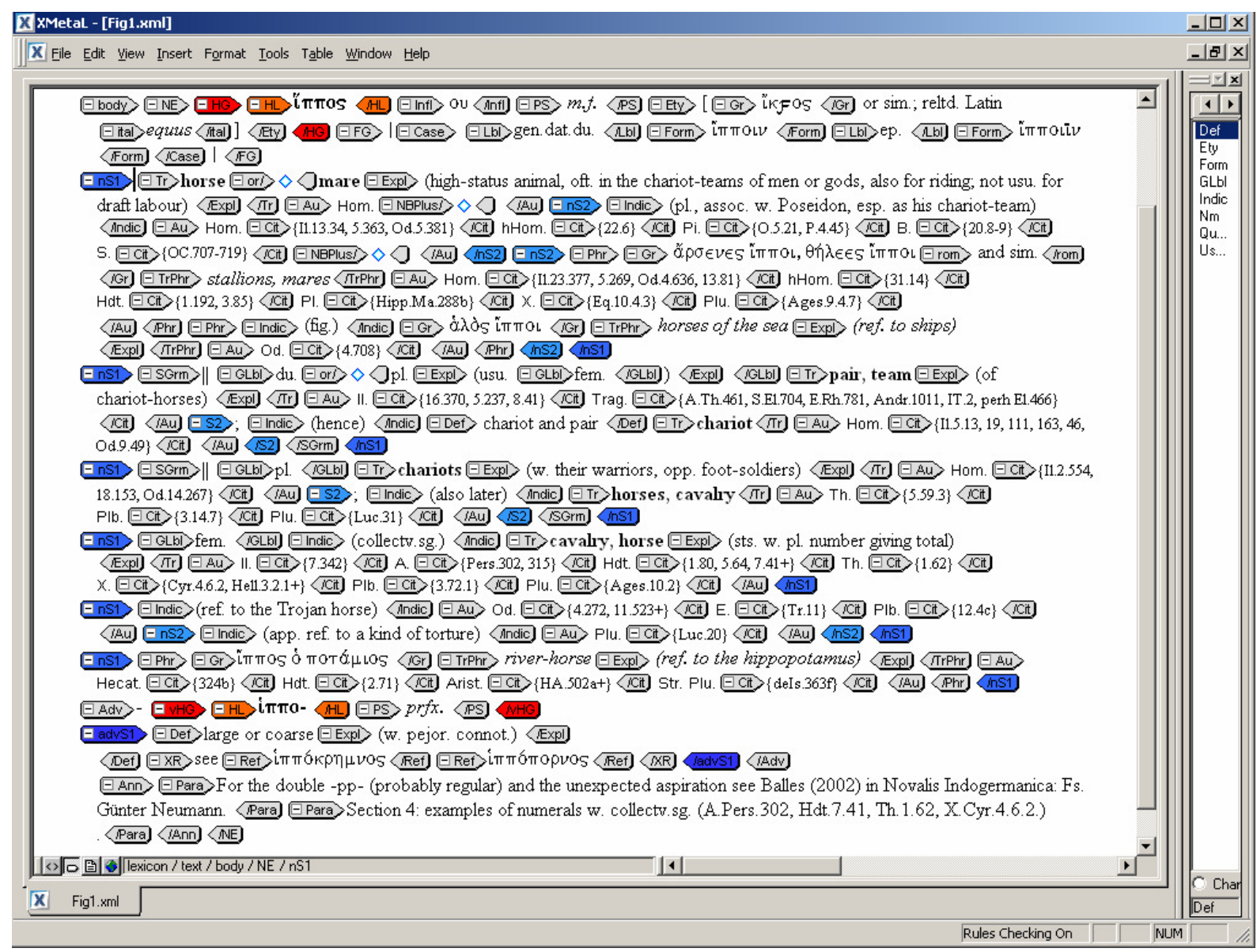

6.5.1. Generic interface. It will be seen that a generic XML editor is used. ${ }^{32}$ It has been suggested that this looks very archaic, and that a unified dictionary production system (DPS) could give a smoother appearance. And perhaps we might have used a DPS such as OED's PASADENA (Perfect All-Singing All-Dancing Editorial and Notation Application), which their team were kind enough to demonstrate to us. ${ }^{33}$ However, a simpler interface appeared to have four advantages:

when composing new text, the writers also need to see the 'nuts and bolts' of the structure, in order to know their position within the entry, 
when organising the sequences of senses, it is essential to be able to cut-and-paste passages of composed text,

the flexibility of a generic system would be suited to a structure under development, and as noted above in 6.2 , it is helpful to be able to see a group of entries in one view (the neighbouring words, not shown in Figure 4, include many i $\pi \pi 0-$ compounds).

6.5.2. Advantages for the writer. Even this relatively 'raw' view is quite user-friendly, because the underlying structure is clear, without obscuring textual continuity. Rather as in a wordprocessing program, the writer starts with an empty screen, then adds structure and content together, so that the screen is never cluttered with empty elements. And, to give a 'smooth' view for proofreading, PDFs (like Figures $1-3$ ) are continuously generated.

In the PDFs, all inter-element white-space and punctuation is added automatically by the stylesheets, and, due to the highly-constrained DTD, we found that this can be done even within mixed-content parent elements, so structure can be added in the XSL as well as the XML: this is discussed in Fraser (2005).

6.5.3. Integrating the research data. It can be seen that there is more information in the XML than in the PDF, in two respects. First, the author abbreviations are accompanied by citation numbers, so that, in our forthcoming online edition, readers will be able to refer to the textual passages. Secondly, our work-notes are integrated in each entry. In this one, there is a reference to etymology (the aspiration and the double 'p'), and a note on the use of numbers with the collective singular in section 4 . There is no limit to the size of the annotations, and so this facility ensures that we do not lose any of the information gathered during the writing process. 
6.5.4. Variably-constrained multiple choice. The benefit of having different types of elements at the higher and lower levels was mentioned above in 6.4.1. The resulting constraint on the choice of elements can be seen in Figure 4: if we identify the position of the computer cursor (the vertical bar just to the left of the word 'horse', fourth line), and then look at the list of possible elements which can be inserted at that point (visible in the right-hand window), we can see that there is a choice of eight. It would be possible to add a definition, an introductory parenthesis, derivational information, or several kinds of grammatical labels, but nothing else: an author name, for instance, cannot be entered here. And at the lower levels, in the mixed-content elements, there is an even more constrained choice of elements (a maximum of five).

This specificity helps us to maintain consistency in style, and in the semantic and grammatical information. It is always clear to the writers if a verbal subject has mistakenly been omitted, or if there is an ambiguity between a transitive or intransitive sense. An entry of any required complexity can be built, using a total array of only 100 elements, whose functions can be easily learned. For this reason, the system can also serve as a training tool for new writers, by guiding them through the entry structures.

\subsection{User-design and creative freedom}

The value of this system lies not in any technical features, but in the user-design approach, because that allowed a close mapping with the lexicographic methodology. Our requirements were met by a flexible system whose design could develop in tandem with our writing. No doubt, other benefits could have been derived from more complex technology, but, for an extended development process, simplicity has proved to be an advantage. And it has constituted a publishing revolution for the group, because the writers can effectively be the typesetters, and the function of the publisher is substantially reduced. This gives us considerable creative freedom, which has been very beneficial for the project. ${ }^{34}$ 


\section{Conclusion: lexicography, semantics and context}

It was noted above that the problem of integrating the historical dimension within a semantic framework has not been entirely solved. All modern dictionaries with a diachronic scope, however novel their approach, still depend on the 'logical' framework described in 2.2.2. However, an increased attention to context gives us an opportunity to introduce new data.

The process of identifying and collating this contextual information is a complex task. Digital structuring is therefore invaluable to the writers, by providing a regular framework within which to organise the data, and to re-examine the established meanings.

Presenting meanings in their contexts is also helpful for the reader. As Quine (1992: 58) observed, the business of dictionaries is 'to teach the use of sentences.' It is not the lexicographer's task to isolate a word and display it on the page, as a lepidopterist displays a butterfly, but rather to describe its behaviour, as far as possible in its native habitat: that is, with its companion words. And we hope that giving this information will stimulate the reader to return to the texts, with an enhanced understanding of how the word behaves in the system of its own language. 


\section{Notes}

${ }^{1}$ This paper expresses the author's personal views. Information on the Cambridge Greek-English Lexicon is available online at www.classics.cam.ac.uk/glp/. Information on the Diccionario griegoespañol is online at www.filol.csic.es/dge/index.htm.

${ }^{2}$ The presentation of form is most problematic for verbal entries: see Chadwick (1994: 2).

${ }^{3}$ Zgusta (1987: 259) describes the lexicographic contrast between these terms. For the earlier approach to etymology as the basis for meaning, see Richardson (1836 - 1837, Volume 1: Preface). ${ }^{4}$ This includes Frisk (1960 -1970), Chantraine (1968), Beekes 2010), and Beekes (1969) and Peters (1980) on laryngeals. Of course, derivations are not always clear, and there may also be differing interpretations of them. Adrados, for example, makes a division of the laryngeals into palatal and velar types: see DGE (Volume 1, Prologo: xxxvii).

${ }^{5}$ The principal digital library of Greek texts is the Thesaurus Linguae Graecae (TLG), online at www.tlg.uci.edu/ and also available on CD-ROM.

${ }^{6}$ The protocols developed by the DGE are described in Adrados and Somolinos (1994), and Somolinos and Berenguer (2005). The GI used search software designed by the Scuola Normale Superiore di Pisa: see snsgreek.sns.it/sns.html, and their team has also built an online archive of rarely-attested Greek words, at www.aristarchus.unige.it/pawag/.

${ }^{7}$ The lettering and numbering are the same in all three dictionaries, though the terminology here is taken from the OED. See Zgusta (1989) and Silva (2000) for LSJ and OED, Adrados (1986a: 21) for the DGE.

${ }^{8}$ This is not only a typographical problem (due to constraints on space), but is integral to any linguistic (rather than diagrammatic) description: Chadwick (1996: 12) comments that 'the true relationship of the senses is too complex to be represented by less than a three-dimensional model.' ${ }^{9}$ Zgusta (1987: 264-72) gives details of the changes in Liddell and Scott's approach. 
${ }^{10}$ The term 'ascent' and the accompanying quotation both imply an analogy with biological evolution.

${ }^{11}$ In Chomskian linguistics, scope is understood in terms of 'c-command' (a constituent's relation with its siblings and dependents in parse trees).

12 Though perhaps not everyone would agree with this example, most would consider plant more abstract than tree.

${ }^{13}$ This principle appears to relate closely to topicality within the sentence. See Yamamoto (1999).

${ }^{14}$ On colour terms in Greek, see Wallace (1927) and Irwin (1974). The semantic complexities exemplify a contextual factor discussed in section 4.2: that an adjective (and colour terms are primarily adjectival) cannot be fully described without considering the nouns it qualifies.

${ }^{15}$ On grammaticalisation, see Lehmann (1995), Ramat and Hopper (1998).

${ }^{16}$ Hiorth (1955) notes that this principle was also used by Funk and Wagnall's New Standard Dictionary of 1913, and a brief but useful critique of it is given by Zgusta (2006: 106 - 7).

${ }^{17}$ See Chadwick (1996: 20), and, for an extended discussion of verbal aspect and Kühner's Aktionsart, Porter (1989).

${ }^{18}$ For more on syntactic information in dictionaries, see Adrados (2005), and on prepositions see Adrados (1986b). Even more criteria have been proposed for ordering the senses: Zgusta (2006: 86 n.41) cites Gold (1983) as listing seven, though most are just variations on what is described here. ${ }^{19}$ Within each sense, chronological and distributional information is given by the authorial citations. Presenting these additionally to the semantic information, as in OED and OLD, creates what Zgusta (1989: 190, 199, 220) calls double articulation.

${ }^{20}$ The links between Poseidon, horses, and the sea are celebrated in Sophocles, Oedipus at Colonus 707-719. On the cults of Poseidon, see Schachermeyr (1950: 13 - 108).

${ }^{21}$ This format is inspired by the practice of the GI. 
${ }^{22}$ This argument is agnostic on whether the governing element of the clause is the subject, as in traditional grammar, or the verb inflection, as in Chomsky (1982). The two views may be reconciled by an interpretation of government as a form of agreement: see Chomsky (1992: 7 - 8).

${ }^{23}$ See the Thematic Relations Hypothesis of Jackendoff (1983: 188 - 211).

${ }^{24}$ The formatting of ó $\tau \mathrm{L}$ as two words in the texts of Iliad 14.195 shows an editorial attempt to make a distinction from the conjunction ö $\tau$.

${ }^{25}$ This approach appears to have potential for lexicographic development, though it cannot at present map derivational meaning (see Section 1.2.1), or the variables of usage which are discussed in Section 2 of this paper.

${ }^{26}$ Grammatical words: c. $422=1 \%$ (c. 20 prepositions +40 'improper' adverbials +55 subordinating conjunctions +25 other particles +282 adverbials in $-\theta \varepsilon(v),-\theta \iota$ and $-\delta \varepsilon)$; verbs in $-\omega,-\mu \alpha \mathrm{L}$ and $-\mu$ เ c. $10,672=29 \%$; nouns and adjectives $25,373=70 \%$ (with about a third of the 8,925 adjectives ending in -os, c. 3,000 $=8 \%$ of the whole, also with adverbial forms).

${ }^{27}$ In RDMS, information is stored and displayed in fields. See Codd (1970) for the underlying principles.

${ }^{28}$ On the Dicionário de Grego-Português, see lexiconpt.no.sapo.pt/.

${ }^{29}$ On the TEI structure, and the possibilities for adapting it to new dictionaries, see SperlbergMcQueen and Burnard (1994), Tutin and Véronis (1998).

${ }^{30}$ Although an XML schema could have offered great contextual specificity, a DTD appeared to have advantages for an authorial system, as discussed below.

${ }^{31}$ Standard-content elements contain only other elements, with no free text.

${ }^{32}$ We use XMetaL software, whose 'tags-on' view is shown in Figure 4. No attempt is made here to recommend any particular software: the argument of this paper is that the digital structure should reflect the structure of the lexicographic entries.

${ }^{33}$ The generic features of the PASADENA DPS are described at www.idm.fr/products/dictionary_writing_system/27/. 
${ }^{34} \mathrm{~A}$ business model of user-led innovation appears to be particularly suited to the IT and publishing sectors. See Hippel (2005).

\section{References}

\section{A. Dictionaries}

Beekes, R. S. P., with the assistance of van Beek, L. 2010. A Greek Etymological Dictionary, 2 volumes, Leiden: Brill (translation and revision of H. Frisk 1960 - 1970).

Chantraine, P. 1968. Dictionnaire étymologique de la langue grecque, Paris: Klincksieck.

DGE 1980 - . Adrados, F. R., Gangutia, E., et al. Diccionario griego-español, Madrid: Consejo Superior de Investigaciones Científicas.

Frisk, H. 1960 - 70. Griechisches etymologisches Wörterbuch, 2 volumes, Heidelberg: Winter.

GI 2004. Montanari, F. et al. GI: Vocabolario della lingua greca (First edition 1995.) Turin: Loescher.

IGL 1889. Liddell, H. G. An Intermediate Greek Lexicon: Founded upon the Seventh Edition of Liddell and Scott's Greek-English Lexicon, Oxford: Clarendon.

LFgrE 1955 -. Snell, B., Mette, H. J., and Meier-Brügger, M. Lexikon des frühgriechischen Epos, Göttingen: Vandenhoeck \& Ruprecht.

Liddell, H. G. and Scott, R. 1843. A Greek-English Lexicon: Based on the German work of Francis Passow, Oxford: University Press.

LSJ 1925 - 1940. Liddell, H. G. and Scott, R., revised by H.S. Jones, with the assistance of R. McKenzie, A Greek-English Lexicon: a New Edition, published in ten Parts, Oxford: Clarendon.

LSJ Revised Supplement 1996. Glare, P. G. W., with the assistance of Thompson, A. A. GreekEnglish Lexicon: a Revised Supplement, Oxford: Clarendon. 
Morris, W. (ed.) 1969. American Heritage Dictionary of the English Language, Boston: Houghton Mifflin. (Second Edition 1975).

OED 1888 - 1928. Murray, J. A. H. et al. A New English Dictionary on Historical Principles, Oxford: Clarendon. (Reprinted 1933 with the title Oxford English Dictionary).

OLD 1968 - 1982. Wyllie, J. M., Glare, P. G. W. et al. Oxford Latin Dictionary, Oxford: Clarendon.

Passow, F. 1831. Handwörterbuch der griechischen Sprache, Leipzig: Vogel. (New Edition, 1841 $-1857)$.

Richardson, C. 1836 - 1837. A New Dictionary of the English Language, 2 volumes, London: Pickering.

Schneider, J. G. 1797 - 1798. Kritisches griechisch-deutsches Handwörterbuch: beym Lesen der griechischen profanen Scribenten zu gebrauchen, Leipzig: Frommann.

\section{B. Other literature}

Adrados, F. R. 1977a. 'Problemas de lingüística general en relación con la lexicografía. Aplicación a la lengua griega' in F. R. Adrados, E. Gangutia et al. (eds.), $231-258$.

Adrados, F. R. 1977b. 'Organización de los artículos del diccionario. Criterios a seguir' in F. R. Adrados, E. Gangutia et al. (eds.), $259-280$.

Adrados, F. R. 1986a. 'The Greek-Spanish Dictionary and Lexicographic Science.' Lexicographica Series Maior 2: 8 - 32, republished as 'El $D G E$ y la cienca lexicográfica' in F. R. Adrados and J. R. Somolinos (eds.) 2005: 235 - 244.

Adrados, F. R. 1986b. 'Reflexiones sobre los sistemas de preposiciones del griego antiguo a partir del DGE.' Revista Española de Lingüística 16: 71 - 82, republished in F. R. Adrados and J. R. Somolinos (eds.) 2005: 235 - 244. 
Adrados, F. R. 1997. 'More on the Diccionario griego-español' in H. H. Hock (ed.), Historical, Indo-European and Lexicographic Studies: a Festschrift for L. Zgusta on the Occasion of His 70th Birthday, Berlin: Gruyter, 221 - 231.

Adrados, F. R. 2000. 'La Semántica en el Diccionario griego-español' in M. Martinez et al. (eds.), Cien años de investigación semántica, Volume 1, Madrid, 99 - 110, republished in F. R. Adrados and J. R. Somolinos (eds.) 2005, 289 - 300.

Adrados, F. R. 2005. 'Sintaxis y diccionario' in F. R. Adrados and J. R. Somolinos (eds.), 223 233 (expanded version of 'Syntaxe et dictionnaire' in W. U. Dreissler and W. Meid (eds.) 1978, Proceedings of the Twelfth International Congress of Linguists: Vienna, August 28 September 2, 1977, Innsbruck: Institut für Sprachwissenschaft der Universitat Innsbruck, $337-341)$.

Adrados, F. R., Gangutia, E. et al. (eds.) 1977. Introducción a la lexicografia griega, Madrid: Institutio Antonio Nebrija.

Adrados, F. R. and Somolinos, J. R. 1994. 'The $T L G$ Data Bank, the DGE and Greek Lexicography.' Emerita 62: 241 - 251, republished as 'El banco de datos del $T L G$, el $D G E$ y la lexicografía griega' in F. R. Adrados and J. R. Somolinos (eds.) 2005: 193 - 203.

Adrados, F. R. and Somolinos, J. R. (eds.) 2005. La lexicografia griega y el Diccionario griegoespañol, Madrid: Consejo Superior de Investigaciones Científicas.

Beekes, R. S. P. 1969. The Development of the Proto-Indo-European Laryngeals in Greek, translated by T. S. Preston, The Hague: Mouton.

Benveniste, E. 1954. 'Semantic Problems in Reconstruction.' Word 10: 251 - 264, republished in E. Benveniste 1971, Problems in General Linguistics, translated by M. E. Meek, Coral Gables: University of Miami Press, 249 - 264.

Buck, C. D. and Petersen, W. 1944. A Reverse Index of Greek Nouns and Adjectives, Chicago: University of Illinois Press, republished 1970, Darmstadt: Olms.

Casares, J. 1950. Introducción a la lexicografía moderna, Madrid: Consejo Superior de 
Investigaciones Científicas.

Chadwick, J. 1994. 'The Case for Replacing Liddell and Scott.' Bulletin of the Institute of Classical Studies 39: 1 - 11.

Chadwick, J. 1996. Lexicographica Graeca: Contributions to the Lexicography of Ancient Greek, Oxford: Clarendon.

Chomsky, N. 1982. Lectures on Government and Binding, Dordrecht: Foris Publications.

Chomsky, N. 1992. 'A Minimalist Program for Linguistic Theory' in MIT Occasional Papers in Linguistics 1, republished in K. Hale and S. J. Keyser (eds.) 1993, The View from Building 20: Essays in Linguistics in Honor of Sylvain Bromberger, Cambridge MA: The MIT Press, $1-52$.

Codd, E. F. 1970. 'A Relational Model of Data for Large Shared Data Banks.' Communications of the Association for Computing Machinery 13.6: 377 - 387, published online at www.acm.org/classics/nov95/toc.html.

Crane, G. 1991. 'Generating and Parsing Classical Greek.' Literary and Linguistic Computing 6.4: $243-245$.

Elliot, L. 2000. 'How the Oxford English Dictionary Went Online.' Ariadne 24, published online at www.ariadne.ac.uk/issue24/oed-tech/.

Fellbaum, C. (ed.) 1998. WordNet: An Electronic Lexical Database, Cambridge MA: The MIT Press.

Firth, J. R. 1957. 'A Synopsis of Linguistic Theory 1930-55.' Studies in Linguistic Analysis, Oxford: Philological Society, 1 - 31; reprinted in F. R. Palmer (ed.) 1968, Selected Papers of JR. Firth 1952 - 1959, London: Longmans, 168 - 205.

Fraser, B. L. 2005. 'Author-tagging: a Dictionary DTD as Part of the Writing Environment', available online at http://www.dspace.cam.ac.uk/handle/1810/198313.

Fraser, B. L. 2008. 'Lexicographic Slips: Gathering and Organising Contextual Data for Dictionary Entries', in Alexandre Júnior, M. ed. 2008. Lexicon: Dicionário de Grego-Português: Actas 
de Colóquio Internacional (Lisboa, 24-25 de Novembro de 2006), Lexicography and Lexical Semantics: Questions at Issue in the Making of a Greek Lexicon, Lisbon: Centro de Estudos Clássicos: 53-72, available online at http://www.dspace.cam.ac.uk/handle/1810/218323.

Glare, P. G. W. 1987. 'Liddell \& Scott: its Background and Present State' in R. Burchfield (ed.), Studies in Lexicography, Oxford: Clarendon, $1-18$.

Glare, P. G. W. 1997. 'Liddell-Scott-Jones: Then and Now.' Hyperboreus 3: 205 - 217.

Gold, D. 1983. 'Ordering the Senses in a Monolingual Dictionary Entry' in Y. Anderson III (ed.), Papers of the Dictionary Society of North America 1981, Terre Haute: Dictionary Society of North America, $42-49$.

Hiorth, F. 1955. 'Arrangement of Meanings in Lexicography.' Lingua 4: 413 - 424.

Hippel, E. von 2005. Democratizing Innovation, Cambridge MA: The MIT Press, published online at web.mit.edu/evhippel/www/democ1.htm.

Hjelmslev, L. 1935. 'La Catégorie des cas: étude de grammaire générale. Première partie.' Acta Jutlandica 7.1: 1 - 184.

Irwin, E. 1974. Colour Terms in Greek Poetry, Toronto: Hakkert.

Jackendoff, R. 1983. Semantics and Cognition, Cambridge MA: The MIT Press.

Kipfer, B. A. 1984. 'Methods of Ordering Senses within Entries' in R. R. K. Hartmann (ed.), LEXeter '83 Proceedings: Papers from the International Conference on Lexicography at Exeter, 9 - 12 September 1983, Tübingen: Niemeyer, $101-108$.

Lehmann, C. 1995. Thoughts on Grammaticalization (LINCOM Studies in Theoretical Linguistics 01), Munich: LINCOM Europa.

Lyons, J. 1977. Semantics, 2 volumes, Cambridge: Cambridge University Press.

Lyons, J. 1989. ‘Semantic Ascent: a Neglected Aspect of Syntactic Typology’ in D. Arnold, M. Atkinson et al. (eds.), Essays on Grammatical Theory and Universal Grammar, Oxford: Clarendon, $153-186$.

Murray, J. A. H. 1888. 'General Explanations' in OED, Vol. 1, xxiv - xxxiv. 
Peters, M. 1980. Untersuchungen der Vertretung der indogermanischen Laryngale in Griechischen, Vienna: Osterreichische Akademie der Wissenschaften.

Porter, S. 1989. Verbal Aspect in the Greek of the New Testament: with Reference to Tense and Mood, New York: Lang.

Quine, W. V. O. 1960. Word and Object, Cambridge MA: Harvard University Press.

Quine, W. V. O. 1992. 'Meaning' in W. V. O. Quine, Pursuit of Truth, Revised Edition, Cambridge MA: Harvard University Press, 37 - 59.

Ramat, A. G. and Hopper, P. (eds.) 1998. The Limits of Grammaticalization, Amsterdam: Benjamins.

Rice, K. 2000. Morpheme Order and Semantic Scope, Cambridge: Cambridge University Press.

Rydberg-Cox, J. A. 2005. 'Word Profile Tool.' Cultural Heritage Language Technologies, published online at www.chlt.org/CHLT/Slip_Sample/index.html.

Saussure, F. de 1916. Cours de linguistique générale, edited by C. Bally and A. Sechehaye, Lausanne: Payot.

Schachermeyr, F. 1950. Poseidon und die Entstehung des griechischen Götterglaubens, Bern: Francke.

Silva, P. 2000. 'Time and Meaning: Sense and Definition in the $O E D$ ' in L. Mugglestone (ed.), Lexicography and the OED: Pioneers in the Untrodden Forest, Oxford: Oxford University Press, $77-95$.

Simpson, J. A. and Weiner, E. S. C. 1989. 'The New Oxford Dictionary Project' in $O E D$, Second Edition, Oxford: Clarendon, 1 - lvi.

Somolinos, J. R. and Berenguer, J. A. 2005. 'El trabajo de documentación en el Diccionario griego-español', in F. R. Adrados and J. R. Somolinos (eds.) 2005, 105 - 130.

Sperlberg-McQueen, C. M. and Burnard, L. 1994. Guidelines for Electronic Text Encoding and Interchange, Oxford: Text Encoding Initiative, published online at www.tei-c.org/P $4 X /$.

Tompa, F.W. 1996. 'An Overview of Waterloo's Database Software for the OED.' Computing in 
the Humanities Working Papers B.13, first published CHWP 2, 1992, published online at www.chass.utoronto.ca/epc/chwp/tompa/index.html.

Tutin, A. and Véronis, J. 1998. 'Electronic Dictionary Encoding: Customizing the TEI Guidelines' in T. Fontanelle (ed.) Eighth Euralex International Congress (EURALEX '98), Gothenburg: University Press, 4 -8, published online at www.up.univmrs.fr/veronis/pdf/1998euralex.pdf.

Ullmann, S. 1972. Semantics: an Introduction to the Science of Meaning, Oxford: Blackwell.

Wallace, F. E. 1927. Color in Homer and in Ancient Art, Northampton MA: Smith College Classical Studies.

Yamamoto, M. 1999. Animacy and Reference: a Cognitive Approach to Corpus Linguistics, Amsterdam: Benjamins.

Zgusta, L. 1984. 'Translational Equivalence in the Bilingual Dictionary.' Lexicographica Series Maior 1: $147-154$.

Zgusta, L. 1987. 'Derivation and Chronology; Greek Dictionaries and the Oxford English Dictionary (Dvādaśakośyam).’ Lexicographica Series Maior 23: 259 - 281.

Zgusta, L. 1989. 'The Oxford English Dictionary and Other Dictionaries (Aikakośyam).’ International Journal of Lexicography 2.3: $188-230$.

Zgusta, L. 2006. Lexicography Then and Now: Selected Essays, edited by F. S. F. Dolezal and T. B. I. Creamer, Lexicographica Series Maior 129, Tübingen: Niemeyer. 